
\title{
25 Research Suare \\ Help-seeking behavior of individuals with schizophrenia in the general population of Hunan, China
}

\section{Jing Ma}

The Brain Hosital of Hunsn Province

Qiongjuan Zheng

Hunan Provincial Tumor Hospital

\section{Yun Zhang}

Northwest Minzu University

Chunyu Liu

Department of Psychiatry,Department of Neurosience \& Physiology,SUNY Upstate Medical University

\section{Xuefei Tian}

Hunan University of Chinese Medicine

Dongxin Wang ( $D$ 46677076@qq.com )

The Brain Hospital of Hunan Province

\section{Xuejun Liu}

The Brain Hospital of Hunan Province

\section{Research article}

Keywords: Schizophrenia, help-seeking behavior, family history of mental disorders, education level, access to mental healthcare

Posted Date: April 3rd, 2020

DOI: https://doi.org/10.21203/rs.3.rs-20778/v1

License: (c) (1) This work is licensed under a Creative Commons Attribution 4.0 International License. Read Full License 


\section{Abstract}

Purpose: This study aims to know the seeking help behavior (including seeking help or not, first choice, influential factors and barriers in seeking help) of individuals with SZ in Hunan province of China.

Methods : The participants are from a larger epidemiological study of severe mental disorders in Hunan province of China. Self-made questionnaires were used to collect relative information.

Results : 1) Of the 367 participants, $68.9 \%$ (253/367) sought help; of those, $64.6 \%(n=163)$ pursued professional psychiatric services and $30.8 \%(n=78)$ pursued non-medical options (i.e., relatives, praying to Buddha) as the most common first choices. 2) The help-seeking behavior ratio (seeking help individuals/total sample size) is significantly lower in the illiterate group than in other education levels. Those with a family history of mental disorders tend to have a higher help-seeking behavior ratio. And the first choice of help is largely related to education level. 3) Frequent reasons behind not seeking help include fear of stigmatization (72.9\%), poor mental health literacy (64.5\%), concerns over cost (50.6\%), and limited access to medical services (47.0\%).

Conclusion : About one third of the individuals do not seek help. Individuals with SZ tend to choose psychiatric hospital and relatives as their first choice. A family history of mental disorders and higher education levels are meaningfully associated with help-seeking behavior, and individuals with more education tend to seek for professional help first. The primary reasons for not seeking help include fear of stigmatization, lack of awareness about mental illness, concerns over cost, etc.

\section{Background}

Schizophrenia (SZ) is a chronic, recurrent and severe mental disorder prevailing in about $0.63 \%$ to $0.94 \%$ of the population (with an average annual rate of $0.81 \%$ )[1].Most people with $\mathrm{SZ}$ benefit from antipsychotic treatment[2]with early diagnosis being critical. Unfortunately, many individuals with SZ avoid getting help, estimates of $20 \%$ to $70 \%$ do not seek for help worldwide as shown in previous studies [3]. Many factors influence whether or not individuals with mental disorders seek-help, such as gender, location of, annual income, type of medical insurance, marriage status, stigma and other social and culture factors[4-7]. However, research focusing on whether or not individuals with SZ seek help is rare. Among those who do seek help, the first choice has recently attracted more attention. Early diagnosis of SZ can be very challenging because of patients' hesitation or refusal in seeking help, especially professional help. For instance in Saudi Arabia, Only 40\% individuals with SZ have had first contact with a health professional [8]. Shi and colleague's study in China showed that $63 \%$ of individuals with SZ first sought help from non-psychiatric medical sources [9]. Many previous studies found that $16 \%$ to $76 \%$ of individuals with SZ seek help from relatives, friends, traditional/faith healers and religion [10-16]. Moreover, the longer individuals have suffered from SZ, the lower their remission and recovery rates[17].Experiencing SZ without treatment can mean more serious damage to social functioning, one's own physical health, and the safety of others [18-19]. Some research concludes that common choices 
for help include psychiatric hospitals [16], general hospitals [20], and psychotherapy [21]. Studies worldwide show that the most common first choices for individuals seeking help are general practitioners, traditional/faith healers and psychiatrists[20,22]. Yalvac and colleague's study (2017) show psychiatrists as the most common first choice for urban dwellers in Turkey [16].

We hypothesize that the help-seeking ratio in china is low and people tend to ask for help firstly in such non-professional way as traditional/faith healers, superstition, etc. This study aims to determine the helpseeking ratio and first choice of help for individuals with SZ living in the Hunan province of China.

\section{Methods}

\section{Sampling procedures}

The survey had two stages. The initial screening stage used a modified 12-item general Health Questionnaire (GHQ-12) and a severe mental disorders clue questionnaire [23-24]. The degree of risk (high/middle/low) was assessed according to the GHQ-12scoring.

The second stage involved diagnostic investigators, doctors from psychiatric hospitals who attended a unified training on SCID-I/P \Structured Clinical Interview for Diagnostic and Statistical Manual of Mental Disorders Fourth Edition, Text Revision Axis I Disorders, Research Version, Patient Edition, SCID-I/P区. The investigators used SCID-I in all participants suspected of being at high-risk and $30 \%$ of those suspected of having a middle-risk suspected participants. For difficult diagnoses, two experts discussed the patient and then determined the diagnosis in consensus. A total of 539 individuals with schizophrenia (SZ) were eventually diagnosed within the second stage.

Informed consent was obtained before interviewing. All study content was approved by the Ethics Committee of the Brain Hospital of Hunan Province (the Second People's Hospital of Hunan Province). The privacy of respondents was considered and protected carefully.

A self-administered questionnaire was used to collect the following information: whether or not individuals with SZ have sought help, the first choice for help, the main reason for not seeking help, whether or not the individual has medical insurance, the self-pay ratio of medical insurance(amount paid by the patient/total cost for medical services), monthly family income, numbers of public disruptions, self-injury and suicidal behavior, risk assessment囚Level 5: Violence against others, arson, explosion, etc.; Level 4: Repeated smashing behavior, regardless of occasion, against property or people and cannot be persuaded to stop (including suicide). Level 3:Smashing behavior, regardless of occasion, against property and cannot be persuaded to stop. Level 2: Smashing behavior against property, confined to the home, and can be persuaded to stop. Level 1: Verbal threats and shouting without hitting. Level 0: None of the above behavior.囚This study collected the education level, family history of mental disorders, gender, and demographics from all 367 individuals with SZ. 


\section{Participants}

The participants of this study were from a larger epidemiological survey study of severe major mental disorders in Hunan province. The original study used stratified, clustered, and random multistage sampling with a sample size of 72999 community participants aged 15 years and over from 123 counties and districts within the Hunan province [25].

\section{Statistical analyses}

Frequency analysis of help-seeking behavior, the reasons of non-help seeking behavior and the first choice of those seeking help was conducted using IBM SPSS statistics. We also analyzed the impacts of gender and education level on the first choice of help using correlation testing. We analyzed the relationships between help-seeking behavior and gender, family history of mental disorders, monthly family income, whether medically insured, the ratio of self-payment for publicly funded healthcare (selfpay ratio), trouble-making publicly disruptive behavior, self-injury, suicide attempt, risk assessment, urban or rural residence, and education level in the $367 \mathrm{SZ}$ individuals, using the chi-square test or Fisher's exact test. In consideration of the potential interaction between various influencing factors, we conducted stepwise logistic regression analysis to study the each factor's impact on the help-seeking behavior. We included all the $p<0.1$ (univariate binary logistic regression test) factors in the model.

\section{Results}

There were 539 individuals with SZ screened from the epidemiological study mentioned above, and 367 individuals who finished the current study questionnaires were recruited into this study.

\section{Seeking help versus not seeking help, and influential factors}

\subsection{Statistical description of help-seeking behavior}

Two-hundred and fifty three out of a population of 367 (68.9\%) individuals with SZ sought help, while $31.1 \%$ did not.

1.2 The influential factors for help-seeking behavior

Crosstabs, an SPSS procedure, demonstrated that one's family history of mental disorders, self-pay ratio and level of education were significantly related to help seeking-help- or- not behavior in individuals with $S Z(X 2=6.621, P=0.010 \otimes X 2=12.821, P=0.005 \otimes$ Fisher exact $P=0.0225)$.

After pairwise comparison using the chi-square test or Fisher's exact test, we found that the help-seeking behavior ratio is significantly higher in the $30 \%$ to $60 \%$ self-pay ratio(self-pay fee/total medical 
expenditure) group than in the $10 \%$ to $30 \%$ self-pay ratio group (chi-square $8.40, p=0.00375$, respectively), with no significant difference in other self-pay groups. Nevertheless the help-seeking behavior ratio is significantly lower in the illiterate group than in the groups with primary education, junior high school education and senior high school education (the chi-square and p-value are 4.4557, 0.0348; 6.118, $0.0134 ; 11.019,0.000902$; respectively). No significant differences in help-seeking behavior exist between other self-pay and educational level groups. The patient group with a family history of mental disorders tend to have a higher help-seeking behavior ratio (chi-square and p-value are 6.621, 0.010, respectively). Furthermore, no significant differences in help seeking behavior(or non-help seeking behavior) exist contingent on the degree of self-pay insurance or educational level.

Similarly, help-seeking versus non-help-seeking behavior is not contingent upon gender, monthly family income, medical insurance, publicly disruptive behavior, self-injury, suicide attempts, risk assessment, or urban-rural residence (Table1).

Table 1: Comparison in help-seeking verses non help-seeking behavior based on influencing factors 


\begin{tabular}{|c|c|c|c|c|c|c|}
\hline \multicolumn{7}{|l|}{ Gender } \\
\hline male & 180 & 118 & 62 & \multirow[t]{2}{*}{1.887} & \multirow[t]{2}{*}{0.170} & \multirow[t]{2}{*}{0.170} \\
\hline female & 187 & 135 & 52 & & & \\
\hline \multicolumn{7}{|c|}{ Family history of mental disorders } \\
\hline Yes & 31 & 29 & 2 & \multirow[t]{2}{*}{6.621} & \multirow[t]{2}{*}{0.010} & \\
\hline No & 189 & 136 & 53 & & & 0.021 \\
\hline \multicolumn{7}{|l|}{ Monthly family income } \\
\hline$<1000 ¥$ & 137 & 90 & 47 & \multirow[t]{4}{*}{6.351} & \multirow[t]{4}{*}{0.096} & \\
\hline $1000-3000 ¥$ & 151 & 100 & 51 & & & \\
\hline $3000-5000 ¥$ & 62 & 51 & 11 & & & 0.075 \\
\hline ㄴ $5000 ¥$ & 17 & 12 & 5 & & & \\
\hline \multicolumn{7}{|l|}{ Publicly funded healthcare } \\
\hline Yes & 362 & 250 & 112 & & \multirow[t]{2}{*}{0.648} & \\
\hline No & 5 & 3 & 2 & & & 0.000 \\
\hline \multicolumn{7}{|l|}{ Self-pay ratio } \\
\hline $10 \%$ & 39 & 31 & 8 & \multirow[t]{4}{*}{12.821} & \multirow[t]{4}{*}{0.005} & \\
\hline $10-30 \%$ & 231 & 144 & 87 & & & A $\cap \Omega$ \\
\hline $30-60 \%$ & 75 & 61 & 14 & & & 0.004 \\
\hline $60 \%$ & 22 & 17 & 5 & & & \\
\hline \multicolumn{7}{|c|}{ Number of public disruptions } \\
\hline Yes & 37 & 21 & 16 & \multirow[t]{2}{*}{2.087} & \multirow[t]{2}{*}{0.149} & 0151 \\
\hline No & 187 & 129 & 58 & & & (.1.1 \\
\hline \multicolumn{7}{|l|}{ Self-injury } \\
\hline Yes & 4 & 4 & 0 & & \multirow[t]{2}{*}{0.307} & 0900 \\
\hline No & 215 & 144 & 71 & & & 0.999 \\
\hline \multicolumn{7}{|l|}{ Suicide attempt } \\
\hline Yes & 4 & 3 & 1 & & \multirow[t]{2}{*}{1.000} & 0716 \\
\hline No & 214 & 144 & 70 & & & 0.140 \\
\hline \multicolumn{7}{|l|}{ Risk assessment level } \\
\hline $\mathrm{F}$ & 3 & 1 & 2 & & 0.0787 & \\
\hline $\mathrm{E}$ & 11 & 5 & 6 & & & \\
\hline $\mathrm{D}$ & 40 & 22 & 18 & & & \\
\hline $\mathrm{C}$ & 64 & 43 & 21 & & & 0.098 \\
\hline B & 96 & 72 & 24 & & & \\
\hline A & 152 & 109 & 43 & & & \\
\hline Urban or rural residence & & & & & & \\
\hline urban & 170 & 118 & 52 & 0.033 & 0.855 & 0.855 \\
\hline rural & 197 & 135 & 62 & & & \\
\hline Educational level & & & & & & \\
\hline illiterate & 50 & 25 & 25 & & 0.0225 & \\
\hline primary & 115 & 79 & 36 & & & \\
\hline junior high school & 134 & 95 & 39 & & & \\
\hline senior high school & 41 & 35 & 6 & & & 0.025 \\
\hline secondary school & 14 & 10 & 4 & & & \\
\hline post-secondary school & 5 & 4 & 1 & & & \\
\hline undergraduate or above & 8 & 5 & 3 & & & \\
\hline
\end{tabular}

In consideration of potential interactions between various influencing factors, we used stepwise logistic regression analysis to study each factor's impact on help-seeking behavior. We included all the $p<0.1$ 
(univariate binary logistic regression test) factors, which included family history of mental disorders, monthly family income, self-pay ratio, publicly disruptive behavior, risk assessment level and education level) in the model. The result shows that only a family history of mental disorders and education level are significantly related to whether or not the individual with SZ seeks help.

\section{Barriers to seeking help}

We found that $31.1 \%$ of individuals with SZ from the study population did not seek help. Their reasons are as follows (Figure Legends 1 )

\section{First choices of help-seeking behavior}

\subsection{Statistical description of the first choice of help}

Two-hundred and fifty three out of 367 (68.9\%) individuals with SZ in our study did seek help; for $64.6 \%$ $(n=163)$ of those, the first chose was "professional psychiatric service", with only $41.1 \%(n=104)$ of those admitted to inpatient care. Of the remainder of those seeking help, $30.8 \%$ choose non-medical options, in which 18.2\% ( $n=46)$ first asked relatives for help (Figure Legends 2).

3.2 The impact of gender and education level on the first choice of help

The first choice of help is significantly related to education level but not significantly related to gender in the 253 individuals with SZ using Correlation Test (the P values are $0.007 ; 0.853$; respectively).

\section{Discussion}

\section{Key factors determining help-seeking behavior in individuals with schizophrenia}

We identified several key influential factors that determine whether an individual with SZ does or does not seek help.

1.1Education level and a family history of mental disorders are significantly related to help-seeking behavior. Furthermore, the first choice of help is significantly related to education level, with those of greater education more likely to receive professional psychiatric services.

A family history of mental disorders and level of higher education are strongly associated with seeking help. Part of this correlation is that those with a higher level of education tend to have more readily available professional services. Yet, the relationship between a family history of mental disorders and individuals' with SZ help-seeking behavior has not been formally studied. Zafar and colleagues found education level to be significantly associated with the help-seeking behavior [28]. Those with higher 
education may have a greater mental health literacy and an improved recognition of mental disorders. Our findings indicate that whether individuals with SZ seek help or do not seek help depends primarily on how much they know about the disease and their ability to learn more about it.

This research also found that help-seeking behavior is significantly higher in the $30 \%$ to $60 \%$ self-pay ratio group than in the $10 \%$ to $30 \%$ group. This implies that the more people pay themselves, the more likely they are to seek help. This phenomenon may be associated with the special medical insurance model in China. Citizens in China receive greater reimbursement from the government when they choose to receive medical services from hospitals near their residence (for example: if a woman lives in a rural county, she would need to pay only $10 \%$ to $13 \%$ of the cost of treatment at a rural hospital within the same county; whereas, she would need to pay from $30 \%$ to $60 \%$ of the cost if she went to an urban hospital, and nearly $70 \%$ of the cost to be treated further within the province or in another province. This may indicate that people who have more money for healthcare may pay more attention to their health, and maybe those with more money are more medically literate. Which lead to higher help-seeking willingness.

1.2There were no significant differences in whether or not individuals sought help based on gender, monthly family income, having medical insurance, public disruptions, self-injury, suicide attempts, risk assessment, or urban versus rural residence.

Gender, monthly family income, possessing medical insurance, publicly disruptive behavior, self-injury, suicide attempt, risk assessment, urban versus rural residence did not correlate to help-seeking behavior. These negative findings are inconsistent with some previous studies that find patients' gender having a close relationship to whether or not patients sought help. They attribute the correlation of gender to helpseeking behavior to differences between the sexes in causal attribution of their illnesses [29-30]. Karam and colleague's study shows financial concerns as a common barrier for people with mental illness seeking treatment [31]. Kilany (2018) found that healthcare utilization by individuals with severe mental illness influences by medical insurance and urban-rural dispersal [32]. Huang and colleague's 2019 study finds that an individual's perception of a higher severity level indicates greater impetus for treatment [33]. The sample size of our study is not big enough, so we assume that the numbers of public disruptions, self-injury, suicide attempt and risk degree assessment are few and may not be represented in this small sample. Factors including gender, monthly family income and medical insurance, residential did not emerge as related to whether individuals seek help, which may have something to do with the sample source. Uniquely, our population is derived from a community sample, whereas previous studies simply used hospitalized populations. The population of individuals with SZ within the larger community differ from a hospitalized population in the severity of the disease state, with the latter typically more severe than the general population. These populations are not homogeneous.

1.3A disconcerting number of individuals who can be diagnosed with schizophrenia among the general population do not seek help due to common barriers. 
Our study reveals a distressing statistic, that nearly one-third of individuals in the general population who can be diagnosed with SZ do not seek help. Similarly, a study by Zhang and colleagues (2013) found that $28.1 \%$ of patients with mental illness in the urban areas of northern China do not seek any form of help either [26]. These results contradict a study in the rural community of Liuyang, China, which showed far fewer than half of the larger percentages of individuals with SZ not seeking help (only $12.7 \%$ )[27]. This stark contrast may be due to differences in sample sources and study procedures.

In our study, the main reasons for not seeking help include fears of stigmatization and discrimination (72.9\%), poor mental health literacy (64.5\%), concerns over cost of the treatment (50.6\%), and limited access to medical services $₫ 47.0 \% \bigotimes$. Research from Mavrogiorgou (2015) shows that roughly $40 \%$ of their study participants reported fears of stigmatization and discrimination as major barriers to help-seeking behavior[34]. Other research also found stigmatization as a serious impediment to obtaining help [35]. Furthermore, Ho and colleagues (2008) pointed to the lack of knowledge about available treatment, the inability to afford the high cost of treatment, and lack of transportation as the pivotal barriers [36]. One study of individuals in Ningxia, China found that a general lack of mental health literacy and limited access to specialized medical institutions were the predominant reasons that individuals with severe mental illness chose non-specialized hospitals or did not seek medical treatment [37]. The exact same barriers predominated in our study as well, which indicates that to a large degree social factor dictate help-seeking behavior. Increased social tolerance and acceptance of SZ, improved general awareness of SZ and strengthened access to professional psychiatric services are needed.

\section{First choices for help-seeking behavior}

2.1Professional psychiatric services and non-medical options are the preferred resource for individuals with SZ who seek help, with over twice as many choosing professional psychiatric services $(64.6 \%, n=$ $163)$ over non-medical options $(30.8 \%, n=78)$. The top three choices of non-medical options include relatives, praying to Buddha, and traditional and/or faith healers. This study found psychiatric hospital and relatives to be the most common first choices of individuals with SZ seeking help, whereas some studies show psychiatrists and psychiatric hospitals as the most common first choices[16].Nonetheless, other studies show general medical hospitals and physicians as the first choice [10,20]. Such disparity in findings may arise from different medical structure and low accessibility of psychiatrists and mental hospitals. Their results also contradict with ours in that general medical support and hospitalization was the most common first choice. Some study also indicate that religion [15] and traditional/faith healers [12] are the most common first choices. However, our study showed the help-seeking behavior of individuals with SZ in the Hunan province of China is comparatively more scientific. In terms of relatives being an initial means of support, a previous study in southern India states that $16.8 \%$ of late adolescents with SZ seek help from their mothers, [13] while a study from Nigeria declares that $91 \%$ of individuals' first contact of treatment is initiated by relatives [15]. This research indicates that relatives play a very important role in help-seeking behavior of individuals with SZ in Hunan province with family support also 


\section{Novel study design using community-based sampling}

We believe this is the first study that has investigated help-seeking behavior in individuals with SZ using a community sample at a provincial level. It is of great significance for public health, because it offers information about the current situation about seeking help behavior of individuals with SZ in China, and indicates future direction of medical education development. Main limitation of this study was as followings:1)There being too few investigators available for this study, we could not personally interview all of the individuals suspected of having SZ who were screened in the first stage; therefore, a considerable proportion of individuals with SZ may have been missed.2)Our study is a small part of a larger epidemiological study of severe mental illness in the Hunan province, missing values did result the tremendous work load at hand.

\section{Conclusion}

In conclusion, we found that about one third of individuals with SZ in Hunan province do not seek help. The primary reasons for this large percentage include fear of stigmatization, poor mental health literacy, concerns over cost, and limited access to medical services. Individuals who do seek help tend to choose psychiatric hospitals and relatives as their first choice of help. A family history of mental disorders and higher education levels were significantly associated with help-seeking behavior. The first choice of help correlates significantly to education level; correspondingly, those with more education are more likely to access professional services. Our findings indicate mental health literacy is meaningful and important not only to individuals with mental disorders but to their relatives as well. It also indicates that mental health literacy should be augmented in populations with less education and populations without a family history of mental disorders. Our study also indicates that an increased tolerance and acceptance of SZ within the society and improved access to professional medical services should be encouraged in the future.

\section{Abbreviations}

Schizophrenia (SZ)

\section{Declarations}

\section{Acknowledgments}

We would like to acknowledge the support offered by the project of Technological Innovation Guidance Plan of Hunan province $\triangle$ title: a randomized controlled study of the effect of social skills training on Asperger syndrome, 2017SK50314囚and the project of Hunan Provincial Health Committee冈B2015-103). 
We would like to acknowledge the assistance of our peers who gave valuable suggestions in developing this manuscript.

Ethics approval and consent to participate: This study is approved by 'the ethics committee of the Brain Hospital of Hunan Province', the committee's reference number is 'Z2019045'. And written informed consent was obtained from a parent or guardian for participants under 16 years old.

Consent for publication: Not applicable.

Availability of data and material: The datasets used and/or analysed during the current study are available from the corresponding author on reasonable request.

Conflicts of interest/Competing interests: The authors declare that they have no competing interests.

Funding: We would like to acknowledge the support offered by the project of Technological Innovation Guidance Plan of Hunan province $\nabla$ title: a randomized controlled study of the effect of social skills training on Asperger syndrome $\mathbb{2}, 2017$ SK50314区, JM is the recipient of this project. And the project of Hunan Provincial Health Committee『B2015-103), DW is the recipient of this project .

Authors' contributions: All the authors have given valuable suggestions in developing this manuscript. $\mathrm{XL}$, DW and XT collected the data of this article. JM, QZ, YZ, CL all participated in the data analysis, writing and revise of this article.

\section{References}

1. Wu Y, Kang R, Yan Y, Gao K, Li Z, Jiang J, Chi X, Xia L. Epidemiology of schizophrenia and risk factors of schizophrenia-associated aggression from 2011 to 2015. J INT MED RES 2018, 46(10): 40394049 .

2. Miodownik C, Lerner V, Kudkaeva N, Lerner PP, Pashinian A, Bersudsky Y, Eliyahu R, Kreinin A, Bergman J. Curcumin as Add-On to Antipsychotic Treatment in Patients With Chronic Schizophrenia: A Randomized, Double-Blind, Placebo-Controlled Study. CLIN NEUROPHARMACOL 2019, 42(4): 117122.

3. Zheng C. Investigation on mental status and household burden of inpatients with schizophrenia, Fudan university, 2010. (Chinese article with English abstract)

4. Brand E, Rodriguez-Monguio R, Volber R. Gender differences in mental health and substance use disorders and related healthcare services utilization. Am J Addict 2019, 28(1): 9-15.

5. Guan YQ, Zhang M, Zhang X, Zhao ZP, Huang ZJ, Li C, Wang LM. [Medical treatment seeking behaviors and its influencing factors in employed floating population in China]. Zhonghua Liu Xing Bing Xue Za Zhi 2019, 40(3): 301-308.

6. Naik SK, Pattanayak S, Gupta CS, Pattanayak RD. Help-seeking Behaviors Among Caregivers of Schizophrenia and other Psychotic Patients: A Hospital-based Study in Two Geographically and 
Culturally Distinct Indian Cities. Indian J Psychol Med 2012, 34(4): 338-345.

7. Stone L, Finlay WM. A comparison of African-Caribbean and White European young adults' conceptions of schizophrenia symptoms and the diagnostic label. Int J Soc Psychiatry 2008, 54(3): 242-261.

8. Al FH, Lappin J, Murray R, Boydell J. Duration of untreated psychosis and pathway to care in Riyadh, Saudi Arabia. Early Interv Psychiatry 2017, 11(1): 47-56.

9. Shi S, Lu Z, Zhu S. Seeking behavior of patients with mental disorders and interfering factors. Zhonghua Yi Xue Za Zhi 2000, 80(1): 75-78.

10. Jiangchang J. Analysis of schizophrenic seeking treatment behavior and its influencing factors in Foshan area. Chronic Pathemathol J 2014, 15(03): 215-217. (Chinese article with English abstract)

11. Kate N, Grover S, Kulhara P, Nehra R. Supernatural beliefs, aetiological models and help seeking behaviour in patients with schizophrenia. Ind Psychiatry J 2012, 21(1): 49-54.

12. Zhuo Yong-ning, Zheng Hui, Xu Chong-ta. The study of help-seeking behavior before seeing psychiatrist and its related factors in schizophrenic. Chin J of Behavior Med Sci 2005:618-619. (Chinese article with English abstract)

13. Ogorchukwu JM, Sekaran VC, Nair S, Ashok L. Mental Health Literacy Among Late Adolescents in South India: What They Know and What Attitudes Drive Them. Indian J Psychol Med 2016, 38(3): 234-241.

14. Yamasaki S, Ando S, Shimodera S, Endo K, Okazaki Y, Asukai N, Usami S, Nishida A, Sasaki T. The Recognition of Mental Illness, Schizophrenia Identification, and Help-Seeking from Friends in Late Adolescence. PLOS ONE 2016, 11(3): e151298.

15. Odinka PC, Oche M, Ndukuba AC, Muomah RC, Osika MU, Bakare MO, Agomoh AO, Uwakwe R. The socio-demographic characteristics and patterns of help-seeking among patients with schizophrenia in south-east Nigeria. J Health Care Poor Underserved 2014, 25(1): 180-191.

16. Yalvac HD, Mutlu EA, Kotan Z, Ozer I, Karslioglu EH, Caykoylu A. Explanatory Models of IIIness, Help Seeking Behaviours and Related Factors in Patients with Schizophrenia: A Comparative Study from Two Different Provinces of Turkey. Community Ment Health J 2017, 53(8): 951-957.

17. Kohn D, Pukrop R, Niedersteberg A, Schultze-Lutter F, Ruhrmann S, Bechdolf A, Berning J, Maier W, Klosterkotter J. [Pathways to care: help-seeking behavior in first-episode psychosis]. Fortschr Neurol Psychiatr 2004, 72(11): 635-642.

18. Marshall M, Lewis S, Lockwood A, Drake R, Jones P, Croudace T. Association between duration of untreated psychosis and outcome in cohorts of first-episode patients: a systematic review. Arch Gen Psychiatry 2005, 62(9): 975-983.

19. Wilder-Willis KE, Shear PK, Steffen JJ, Borkin J. The relationship between cognitive dysfunction and coping abilities in schizophrenia. SCHIZOPHR RES 2002, 55(3): 259-267.

20. Liu Dong-mei, Wang Zhi-qing, Yang Yong-he, et al. Epidemiological survey of schizophrenia in people aged 18 years and olderin Yibin city. Chin J Public Health 2013;29:1755-1757.(Chinese article with English abstract) 
21. Hugo CJ, Boshoff DE, Traut A, Zungu-Dirwayi N, Stein DJ. Community attitudes toward and knowledge of mental illness in South Africa. Soc Psychiatry Psychiatr Epidemiol 2003, 38(12): 715719.

22. Yang $D$. The patterns of the health care seeking behavior and related factors in the schizophrenic patients. Zhonghua Shen Jing Jing Shen Ke Za Zhi 1992, 25(4): 215-218, 253.

23. LI Mao-sheng, WU Zhi-mei, LI Xiao-shong, et al.Prevalence of bipolar disorder among residents in Hunan province: across-sectional study. Chin J Public Health 2018;34:1065-1069.(Chinese article with English abstract)

24. Goldberg DP, Gater R, Sartorius N, Ustun TB, Piccinelli M, Gureje O, Rutter C. The validity of two versions of the GHQ in the WHO study of mental illness in general health care. PSYCHOL MED 1997, 27(1): 191-197.

25. Wang D, Ma J, Tan L, Chen Y, Li X, Tian X, Zhou X, Liu X. Epidemiology of severe mental illness in Hunan province in central China during 2014-2015: A multistage cross-sectional study. PLOS ONE 2017, 12(11): e188312.

26. Zhang W, Li X, Lin Y, Zhang X, Qu Z, Wang X, Xu H, Jiao A, Guo M, Zhang Y, Li Y, Tian D. Pathways to psychiatric care in urban north China: a general hospital based study. Int J Ment Health Syst 2013, 7(1): 22.

27. Qiwen Z. Mental health Services utilization and related factors among Patients withschizophrenia in rural communities, Central South University[D], 2008.(Chinese article with English abstract)

28. Zafar SN, Syed R, Tehseen S, Gowani SA, Waqar S, Zubair A, Yousaf W, Zubairi AJ, Naqvi H. Perceptions about the cause of schizophrenia and the subsequent help seeking behavior in a Pakistani population - results of a cross-sectional survey. BMC PSYCHIATRY 2008, 8: 56.

29. Chandra PS, Kommu JV, Rudhran V. Schizophrenia in women and children: a selective review of literature from developing countries. Int Rev Psychiatry 2012, 24(5): 467-482.

30. Srinivasan TN, Thara R. Beliefs about causation of schizophrenia: do Indian families believe in supernatural causes? Soc Psychiatry Psychiatr Epidemiol 2001, 36(3): 134-140.

31. Karam EG, Karam GE, Farhat C, Itani L, Fayyad J, Karam AN, Mneimneh Z, Kessler R, Thornicroft G. Determinants of treatment of mental disorders in Lebanon: barriers to treatment and changing patterns of service use. Epidemiol Psychiatr Sci 2018: 1-7.

32. Kilany M, Morrissey JP, Domino ME, Thomas KC, Silberman P. Utilization and Adherence in Medical Homes: An Assessment of Rural-Urban Differences for People With Severe Mental Illness. MED CARE 2018, 56(10): 870-876.

33. Huang D, Yang LH, Pescosolido BA. Understanding the public's profile of mental health literacy in China: a nationwide study. BMC PSYCHIATRY 2019, 19(1): 20.

34. Mavrogiorgou P, Siebers F, Kienast T, Juckel G. [Help-seeking behavior and pathways to care for patients with obsessive-compulsive disorders]. NERVENARZT 2015, 86(9): 1130-1139.

35. Kane JC, Elafros MA, Murray SM, Mitchell E, Augustinavicius JL, Causevic S, Baral SD. A scoping review of health-related stigma outcomes for high-burden diseases in low- and middle-income 
countries. BMC MED 2019, 17(1): 17.

36. Ho KP, Hunt C, Li S. Patterns of help-seeking behavior for anxiety disorders among the Chinese speaking Australian community. Soc Psychiatry Psychiatr Epidemiol 2008, 43(11): 872-877.

37. Li Li, Wang Qiang, Yang Yi.Study on severe mental illness seeking behavior for the first time and influencing factors in Yinchuan city of Ningxia. Ningxia Medical Journal 2012, 34(07): 601-605.

38. Jorm AF. Mental health literacy: empowering the community to take action for better mental health. AM PSYCHOL 2012, 67(3): 231-243.

\section{Figures}




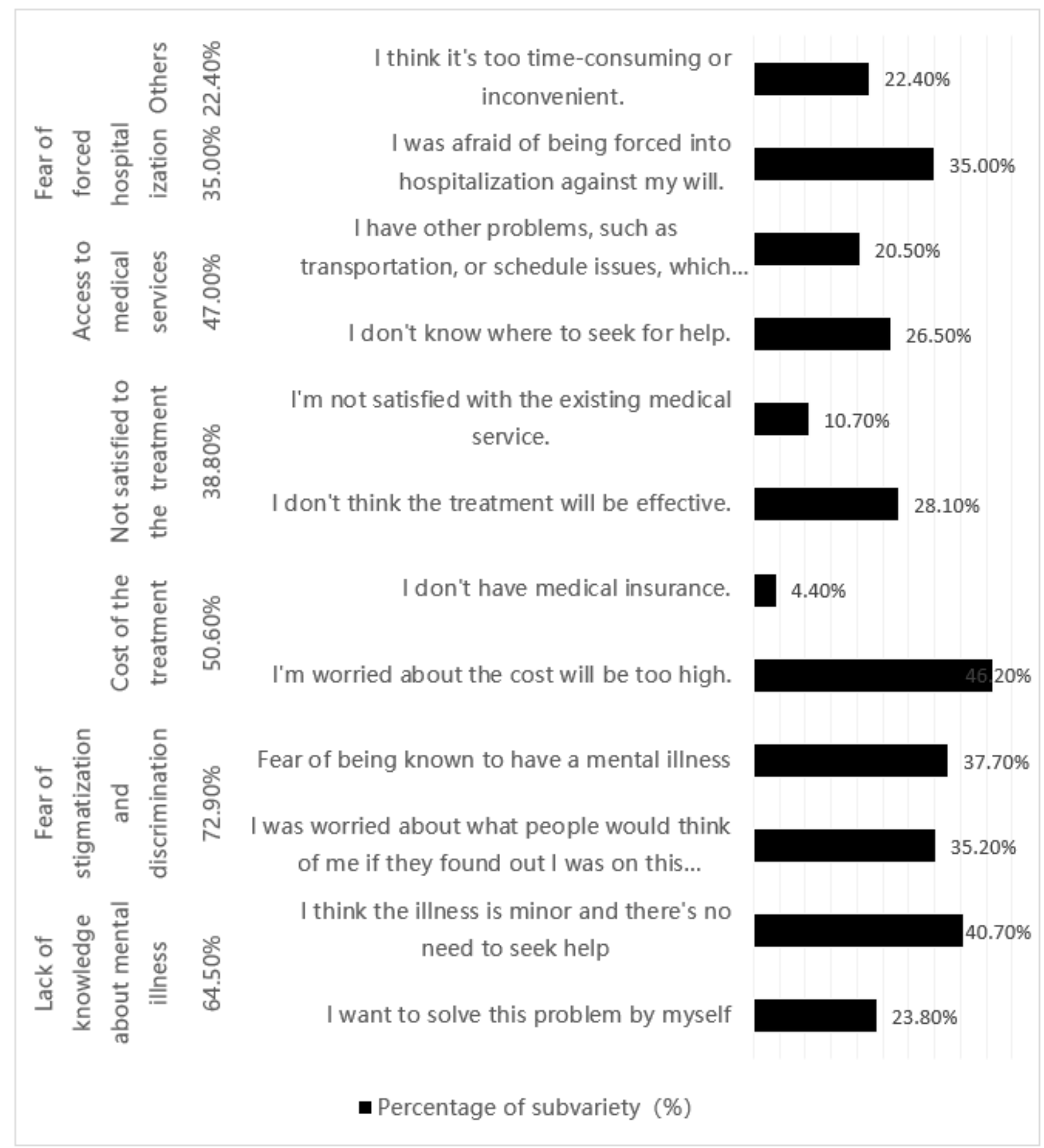

\section{Figure 1}

Reasons for non-help seeking behavior 


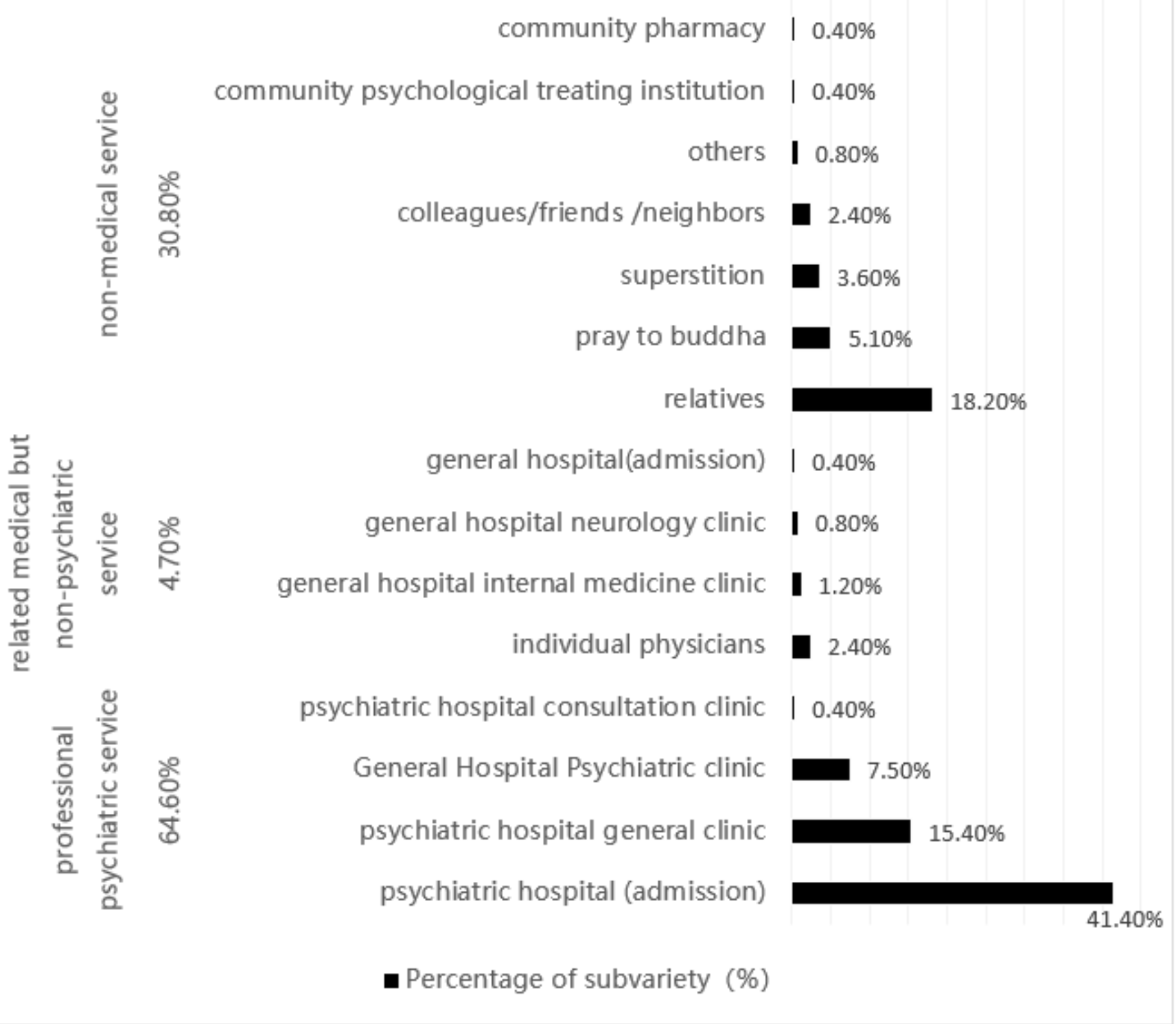

Figure 2

Frequency of the first choice of help for individuals with SZ 